\title{
A Single In Vivo Exposure to Cocaine Abolishes Endocannabinoid-Mediated Long-Term Depression in the Nucleus Accumbens
}

\author{
Lawrence Fourgeaud, ${ }^{1 \star}$ Susana Mato, ${ }^{1 \star}$ Delphine Bouchet, ${ }^{2}$ Agnès Hémar, ${ }^{2}$ Paul F. Worley, ${ }^{3}$ and Olivier J. Manzoni ${ }^{1}$ \\ ${ }^{1}$ Equipe Institut National de la Santé et de la Recherche Médicale Avenir (Plasticité Synaptique: Maturation et Addiction), and ²Unité Mixte de Recherche, \\ Centre National de la Recherche Scientifique 5091, Institut Magendie des Neurosciences, 33077 Bordeaux Cedex, France, and ${ }^{3}$ Department of Neuroscience, \\ The Johns Hopkins School of Medicine, Baltimore, Maryland 21287
}

In the nucleus accumbens (NAc), a key structure to the effects of all addictive drugs, presynaptic cannabinoid CB1 receptors (CB1Rs) and postsynaptic metabotropic glutamate 5 receptors (mGluR5s) are the principal effectors of endocannabinoid (eCB)-mediated retrograde long-term depression (LTD) (eCB-LTD) at the prefrontal cortex-NAc synapses. Both CB1R and mGluR5 are involved in cocaine-related behaviors; however, the impact of in vivo cocaine exposure on eCB-mediated retrograde synaptic plasticity remains unknown. Electrophysiological and biochemical approaches were used, and we report that a single in vivo cocaine administration abolishes eCB-LTD. This effect of cocaine was not present in $D_{1}$ dopamine receptor $\left(D_{1} R\right)-I-$ mice and was prevented when cocaine was coadministered with the selective $D_{1} R$ antagonist 8-chloro-2,3,4,5-tetrahydro-3-5-1h-3-benzazepin-7-ol $(0.5 \mathrm{mg} / \mathrm{kg})$ or with the NMDA receptor (NMDAR) blocker (+)-5-methyl-10,11-dihydro-5H-dibenzo [a,d] cyclohepten-5,10-imine maleate $(1 \mathrm{mg} / \mathrm{kg})$, suggesting the involvement of $\mathrm{D}_{1} \mathrm{R}$ and NMDAR. We found that the cocaine-induced blockade of retrograde signaling was correlated with enhanced expression levels of Homer scaffolding proteins containing the coiled-coil domain and accompanied by a strong reduction of mGluR5 surface expression. The results suggest that cocaine-induced loss of $\mathrm{eCB}$ retrograde signaling is caused by a reduction in the ability of mGluR5 to translate anterograde glutamate transmission into retrograde eCB signaling.

Key words: endocannabinoid; synaptic plasticity; long-term depression; drug abuse; accumbens; mGluR; CB1; $\mathrm{D}_{1} ; \mathrm{NMDA}$; cocaine

\section{Introduction}

There have been considerable efforts in search of the mechanisms underlying the most durable aspects of addiction (e.g., craving and relapse) (Hyman and Malenka, 2001; Nestler, 2001b; Williams et al., 2001). A current hypothesis is that abused drugs cause the remodeling of synaptic functions, and in particular, of activity-dependent synaptic plasticity in brain areas involved in addiction-related behaviors (e.g., the mesocorticolimbic pathway) and/or learning and memory (e.g., the hippocampus) (Hyman and Malenka, 2001; Nestler, 2001a,b; Williams et al., 2001). It has been proposed that these modified neural circuits would be responsible for some of the complex pathological behaviors characterizing addiction. In support of this idea, chronic exposure to

Received Feb. 24, 2004; revised June 15, 2004; accepted June 15, 2004.

Work in 0.J.M.'s laboratory is supported by grants from Institut National de la Santé et de la Recherche Médicale (Programme Avenir), Ministère de la Recherche (Action Concerteé Incitative Jeune Chercheur), Fondation pour la Recherche Médicale, and Région Aquitaine. We thank Dr. D. Robbe for his participation in the initial phase of this project, Dr. Drago (Monash University, Victoria, Australia) for the $D_{1} R-/$ - mice that he generated, Dr. F. Gonon for housing and maintaining these mice in his laboratory, Dr. Ken Mackie for the generous gift of CB1R antibodies, and Drs. A. Schoepp and Monn at Eli Lilly for their generous gift of LY354740.

*L.F. and S.M. contributed equally to this work.

Correspondence should be addressed to Dr. 0. Manzoni, Equipe Institut National de la Santé et de la Recherche Médicale, Avenir (Plasticité Synaptique: Maturation et Addiction), Rue Camille Saint Saëns, 33077 Bordeaux Cedex, France. E-mail: manzoni@bordeaux.inserm.fr.

DOl:10.1523/JNEUROSCI.0671-04.2004

Copyright @ 2004 Society for Neuroscience $\quad 0270-6474 / 04 / 246939-07 \$ 15.00 / 0$ addictive drugs induces alterations of synaptic transmission and/or plasticity in in vitro slice preparations of the ventral tegmental area, nucleus accumbens (NAc), periaqueductal gray, and hippocampus (Ingram et al., 1998; Martin et al., 1999; Thomas et al., 2001; Williams et al., 2001; Beurrier and Malenka, 2002; Harrison et al., 2002; Robbe et al., 2002a; Hoffman et al., 2003).

Long-term treatment with abused drugs does not address the fundamental question of the initial steps leading to addiction: can the first exposure to an abused drug modify (even temporarily) synaptic plasticity and somehow drive selected neuronal circuits into a transient altered state? It has been reported recently that a single exposure to abused drugs (ethanol, cocaine, amphetamine, and morphine have been tested) increased strength at excitatory synapses onto midbrain dopamine cells, suggesting that synaptic plasticity can indeed be an early substrate of addictive-druginduced alterations (Ungless et al., 2001; Melis et al., 2002; Saal et al., 2003).

Because of their putative physiological relevance, forms of synaptic plasticity induced in response to naturally occurring synaptic patterns (or to stimulating protocols mimicking natural synaptic activities) are of obvious particular interest. In this frame of mind, we recently identified the first form of long-term synaptic plasticity involving the endocannabinoid (eCB) system: stimulation mimicking naturally occurring frequencies of the prelimbic cortical afferents to the NAc (for $10 \mathrm{~min}$ at $13 \mathrm{~Hz}$ ) induces a 
robust long-term depression (LTD) of evoked excitatory synaptic transmission (Robbe et al., 2002b). We found that postsynaptic metabotropic glutamate 5 receptors ( $m$ GluR $5 \mathrm{~s}$ ) and presynaptic $\mathrm{CB} 1$ receptors (CB1Rs) are instrumental to eCB-mediated synaptic plasticity: mGluR5s translate anterograde signaling into cannabinoid retrograde signaling and long-term depression. Remarkably, both CB1R and mGluR5 have been implicated in cocaine-related behaviors (Chiamulera et al., 2001; De Vries et al., 2001): a CB1R antagonist induces relapse to cocaine-seeking behavior, and mGluR5-null mutant mice are insensitive to the locomotor-stimulating and rewarding properties of cocaine. These in vivo observations prompted us to directly measure the effects of cocaine exposure on eCB-mediated retrograde signaling in an in vitro NAc slice preparation. We report that a single in vivo exposure to cocaine is sufficient to abolish eCB-mediated LTD (eCB-LTD), and the data suggest a key role for Homer scaffolding proteins and mGluR5 trafficking in the initial synaptic adaptations to cocaine.

\section{Materials and Methods}

Animal treatment. Four-week-old mice [C57BL/6 strain or $\mathrm{D}_{1}$ dopamine receptor $\left(D_{1} R\right)$-null mutant mice] were housed, grouped, and acclimatized to laboratory conditions ( $12 \mathrm{hr}$ light/dark cycle) 1 week before the experiment and had ad libitum access to food and water. Animals received one intraperitoneal injection of cocaine $(20 \mathrm{mg} / \mathrm{kg})$ or vehicle $1 \mathrm{~d}$ before the experiment. Mice were killed the following day, and slices of NAc were prepared as described below. Cocaine $(20 \mathrm{mg} / \mathrm{kg}$; a gift from the National Institute on Drug Abuse, Bethesda, MD) or ( \pm )-1-phenyl2,3,4,5-tetrahydro-(1H)-3-benzazepine-7,8-diol hydrobromide (SKF38393) $(10 \mathrm{mg} / \mathrm{kg}$; Research Biochemicals International, Saint Quentin Fallavier, France) was prepared in a solution of $0.9 \% \mathrm{NaCl}$. A volume of $100 \mu \mathrm{l}$ was injected for mice weighing $20 \mathrm{gm}$. 8-chloro-2,3,4,5-tetrahydro-3-5-1h-3benzazepin-7-ol (SCH23390; $0.5 \mathrm{mg} / \mathrm{kg}$, i.p.) (Goto and O'Donnell, 2001; Brady et al., 2003) and (+)-5-methyl-10,11-dihydro-5H-dibenzo [a,d] cyclohepten-5,10-imine maleate (MK801; $1 \mathrm{mg} / \mathrm{kg}$, i.p.) (Valjent et al., 2001) were injected 5 and $30 \mathrm{~min}$ before cocaine, respectively. Mice bearing a null mutation for $D_{1} R\left(D_{1} R-/-\right.$ mice $)$ were generated by Drago et al. (1994). The $\mathrm{D}_{1} \mathrm{R}-/-$ mutant mice used here were produced by crossing heterozygous males and females. $D_{1} R+/+$ mice, referred to as wild type, were from the same litter as $D_{1} R-/-$ mice. The genotypes of all mice were assessed by PCR.

Slice preparation and electrophysiology. Extracellular field recordings were made from medium spiny neurons in parasagittal slices of mice nucleus accumbens. These methods have been described in detail previously (Robbe et al., 2002b). In brief, 4- to 6-week-old male C57BL/6 mice were anesthetized with isoflurane and decapitated. The brain was sliced $(300 \mu \mathrm{m})$ in the parasagittal plane using a vibratome (Integraslice; Campden Instruments, Leicester, UK) and maintained in physiological saline at $4^{\circ} \mathrm{C}$. Slices containing the NAc were stored for at least $1 \mathrm{hr}$ at room temperature before being placed in the recording chamber and superfused $(2 \mathrm{ml} / \mathrm{min})$ with artificial CSF (ACSF) that contained (in mm): $126 \mathrm{NaCl}, 2.5 \mathrm{KCl}, 1.2 \mathrm{MgCl}_{2}, 2.4 \mathrm{CaCl}_{2}, 18 \mathrm{NaHCO}_{3}, 1.2$ $\mathrm{NaH}_{2} \mathrm{PO}_{4}$, and 11 glucose (equilibrated with $95 \% \mathrm{O}_{2}-5 \% \mathrm{CO}_{2}$ ). All experiments were done at room temperature. The superfusion medium contained picrotoxin $(100 \mu \mathrm{M})$ to block $\mathrm{GABA}_{\mathrm{A}}$ receptors. All drugs were added at the final concentration to the superfusion medium. The recording pipette was filled with ACSF. Both the field EPSP (fEPSP) slope (calculated with a least squares method) and fEPSP amplitude were measured (graphs depict amplitudes). An Axopatch-1D (Axon Instruments, Foster City, CA) was used to record the data, which were filtered at 1-2 $\mathrm{kHz}$, digitized at $5 \mathrm{kHz}$ on a DigiData 1200 interface (Axon Instruments), and collected on a personal computer using Acquis-1 software (BioLogic, Claix, France). To evoke synaptic currents, stimuli (100-150 $\mu \mathrm{sec}$ duration) were delivered at $0.033 \mathrm{~Hz}$ through bipolar tungsten electrodes placed at the prefrontal cortex-nucleus accumbens border. Recordings were made in the rostromedial dorsal accumbens close to the anterior commissure.
Immunoblotting. Mice were decapitated $1 \mathrm{~d}$ after injection, the brains were rapidly removed, and parasagittal slices were prepared as for electrophysiology. The entire nucleus accumbens (including the shell and core) was dissected out and immediately processed as follows: the dissected brain punches were homogenized with a handheld tissue grinder in lysis buffer [ 25 mm HEPES, $150 \mathrm{~mm} \mathrm{NaCl}, 1 \%$ Triton X-100 (Sigma, Lyon, France), and protease inhibitor mixture (Roche France, Neuilly sur Seine, France) $]$ and subjected to centrifugation $\left(10,000 \times g\right.$ at $4^{\circ} \mathrm{C}$ for $10 \mathrm{~min}$ ) to remove insoluble material. Protein quantification was performed using the BCA protein assay kit (Pierce, Brebieres, France) according to the manufacturer's instructions. Samples $(20 \mu \mathrm{g})$ were subjected to SDS-PAGE using a minigel apparatus $(7.5 \%$ for $m$ GluR $2 / 3$ or mGluR5 and $10 \%$ for pan-Homer; Amersham Biosciences, Saclay, France), transferred via semidry apparatus (Bio-Rad, Marnes La Coquette, France) to nitrocellulose membrane, and probed for the proteins of interest. mGluR5 and mGluR2/3 were labeled using rabbit anti-rat antibodies (Upstate Biotechnology, Lake Placid, NY) reactive to a peptide sequence targeted on the $\mathrm{C}$ terminus at a dilution of 1:1000. Homer proteins were probed with a rabbit anti-rat pan-Homer antibody (P.F.W.). The pan-Homer antibody was raised against an $\mathrm{N}$-terminus sequence common to all Homer proteins, and thus recognized both short (i.e., Homer 1a) and long [i.e., Homer isoforms containing the coiled-coil domain (CC-Homer)] forms of Homer. In our experiments, the panHomer antibody recognized only one band at $\sim 45 \mathrm{kDa}$, corresponding to CC-Homer. We verified that in lysates of Homerla- or Homer1btransfected COS7 cells, the pan-Homer antibody recognized a single band at $\sim 25$ and $45-47 \mathrm{kDa}$, respectively (supplemental Fig. 1, available at www.jneurosci.org/cgi/content/full/24/31/6939/DC1). CB1Rs were probed with a rabbit anti-rat antibody reactive to a peptide sequence targeted on the C terminus at a dilution of 1:3000 (Dr. Ken Mackie, University of Washington, Seattle, WA). Labeled proteins were detected using an HRP-conjugated anti-rabbit secondary IgG diluted 1:3000 and visualized with enhanced chemiluminescence (Amersham Biosciences). Immunoreactivity levels were quantified by integrating band density $X$ area using computer-assisted densitometry (NIH ImageJ 1.29). Tubulin (anti- $\beta$-tubulin clone tub2.1; 1:10,000; Sigma) expression was used to normalize protein quantity. The density $X$ area measurements were averaged over two to three control samples for each gel, and all bands were normalized as percentage of corresponding control values. The number of determinations is shown in parentheses, and each individual number corresponds to a single mouse.

Biochemical measurements of surface-expressed mGluR5. Brain slices were prepared as for the immunoblotting experiments (except that slices were $200 \mu \mathrm{m}$ thick) and entire NAcs were dissected out. The microdissected NAcs were immediately put in ice-cold ACSF and then incubated in ACSF containing $1 \mathrm{mg} / \mathrm{ml}$ sulfosuccinimidyl-6-(biotinamido) hexanoate (Pierce) for $1 \mathrm{hr}$ at $4^{\circ} \mathrm{C}$ with gentle shaking. Unreacted biotinylation reagent was removed by two 10 min washes in ice-cold ACSF and quenched by two 20 min washes in ice-cold ACSF containing $100 \mathrm{~mm}$ glycine. The dissected brain punches were then homogenized with a handheld tissue grinder in $150 \mu$ l of lysis buffer [ $25 \mathrm{~mm}$ HEPES, $150 \mathrm{~mm}$ $\mathrm{NaCl}, 1 \%$ Triton $\mathrm{X}-100$ (Sigma), and protease inhibitor mixture (Roche) $]$ and subjected to centrifugation $\left(10,000 \times g\right.$ at $4^{\circ} \mathrm{C}$ for $\left.10 \mathrm{~min}\right)$ to remove insoluble material. A total of $250 \mu \mathrm{g}$ of each lysate was incubated overnight at $4^{\circ} \mathrm{C}$ with $50 \mu \mathrm{l}$ of streptavidin agarose beads (Sigma). The beads were washed three times at $4^{\circ} \mathrm{C}$ in lysis buffer and once in 50 mм Tris-HCl, pH 7.4. The beads were extracted with SDS-sample buffer containing $1 \mathrm{~m}$ dithiothreitol. The biotinylated proteins were analyzed by quantitative Western blotting using anti-mGluR5 antibody as described above.

Data analysis and materials. All values are given as mean \pm SEM. Statistical analyses were done with the Mann-Whitney $U$ test $(p<0.05$ was taken as indicating statistical significance) using Kyplot $\beta .13$ (Koichi Yoshioka, Tokyo, Japan). Of the drugs used, MK801, picrotoxin, and SCH23390 were from Sigma; (+)-2-aminobicyclo-[3.1.0] hexane-2,6dicarboxylic acid (LY354740) was a gift from Drs. A. Schoepp and Monn at Eli Lilly (Indianapolis, IN); all other chemicals were from the highest commercial grade available. 
a

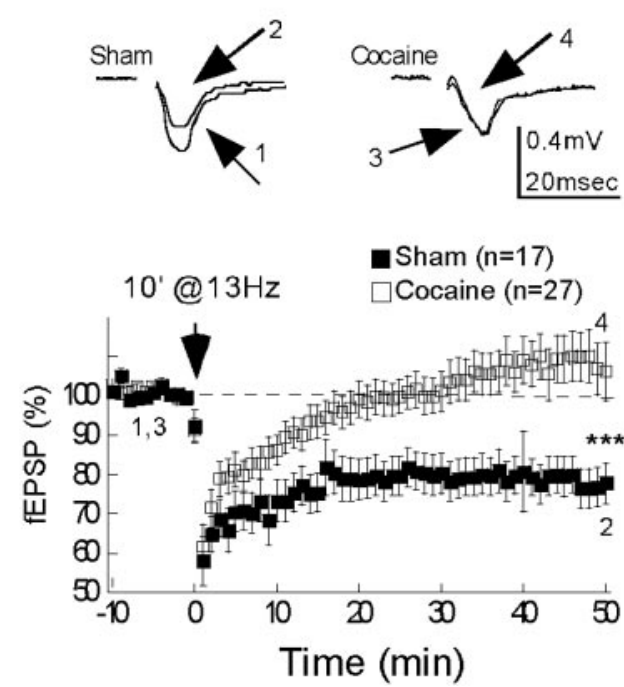

b
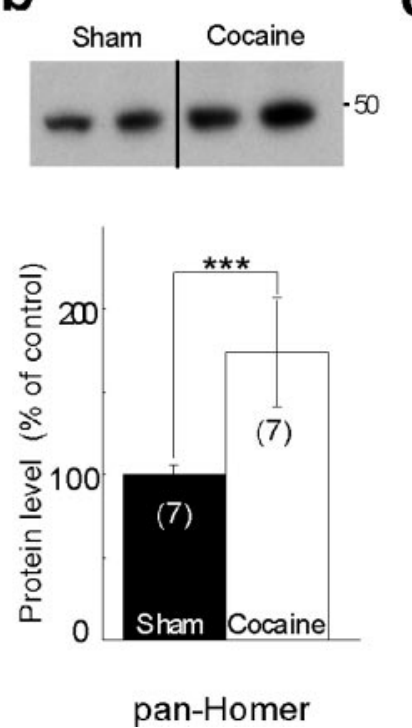

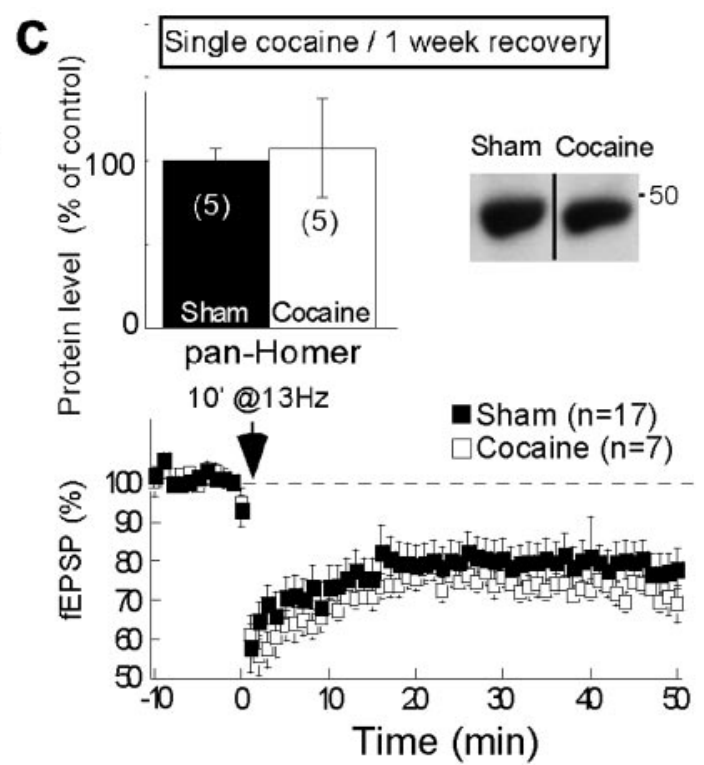

Figure 1. Single in vivo administration of cocaine abolishes eCB-LTD and increases (C-Homer protein levels. a, Top, Sample fEPSPs before (control) or after induction of eCB-LTD in mice injected in vivo with saline (sham) or cocaine $(20 \mathrm{mg} / \mathrm{kg}$ ) taken at the time indicated on graph below. Bottom, Average time courses of eCB-LTD. Single cocaine injection ( $n=27)$ abolished eCB-LTD (compared with sham; $n=17 ; 50$ min after tetanus; ${ }^{* * *} p<0.05$ ). The dashed line represents $100 \% . b$, Representative Western blots of animals administered saline (sham) or cocaine in vivo. The blots show protein levels for CC-Homer using a pan-Homer antibody in the NAc $1 \mathrm{~d}$ after injection. Densitometry measurements are expressed as percentage of control \pm SEM. Single cocaine exposure $(n=7)$ markedly increased CC-Homer protein levels in the NAc, compared with saline $\left(n=7 ;{ }^{* * *} p<0.05\right)$. Immunoblots were quantified by scanning densitometry. $c$, Top, Densitometry measurements expressed as percentage of control \pm SEM and representative Western blots of animals administered saline (sham) or cocaine in vivo. The blots show protein levels for CC-Homer using a pan-Homer antibody in the NAc 1 week after single cocaine injection. One week after a single exposure to cocaine, CC-Homer protein levels were back to normal $(n=5)$ compared with saline $(n=$ $5 ; p>0.05)$. Bottom, eCB-LTD expressed as percentage of baseline 50 min after LTD induction: eCB-LTD was identical 1 week after a single exposure to cocaine $(n=7)$ and in sham mice $(n=17$; $p>0.05)$. The dashed line represents $100 \%$.

\section{Results}

A single in vivo exposure to cocaine abolishes eCB-LTD in the NAc

As reported previously, stimulation mimicking naturally occurring frequencies of the prelimbic cortical afferents to the NAc (10 min at $13 \mathrm{~Hz}$ ) reliably induces a robust LTD of evoked excitatory synaptic transmission termed eCB-LTD (Robbe et al., 2002b; Hoffman et al., 2003) (Fig. 1a). To test whether eCB-mediated retrograde signaling could be part of the early synaptic adaptations to cocaine exposure, we directly compared eCB-LTD in NAc slices prepared from saline- or cocaine-treated mice. Mice were injected once with cocaine $(20 \mathrm{mg} / \mathrm{kg})$ or saline $1 \mathrm{~d}$ before the experiment, a procedure known to cause behavioral sensitization to cocaine (Jackson and Nutt, 1993; Ungless et al., 2001). As shown in Figure $1 a$, a single in vivo exposure to cocaine abolished eCB-LTD, demonstrating that eCB retrograde signaling in the NAc is a synaptic target of cocaine actions.

\section{CC-Homer protein levels are increased after a single in vivo exposure to cocaine}

We next searched for the cellular adaptations triggered by cocaine in the NAc. Behavioral sensitization to cocaine has been correlated with modifications of the relative synaptic weight of AMPA receptors and NMDA receptors (NMDARs) and with related changes in "classical" anterograde synaptic plasticity (Thomas et al., 2001; Ungless et al., 2001; Saal et al., 2003). Retrograde eCBmediated LTD in the NAc is independent of ionotropic glutamate receptors (Robbe et al., 2002b), but in contrast requires the activation of both presynaptic CB1R and postsynaptic mGluR 5 coupled to intracellular $\mathrm{Ca}^{2+}$ stores (Robbe et al., 2002b). The expression levels of intracellular scaffolding proteins of the Homer family are modulated by cocaine (Swanson et al., 2001; Fagni et al., 2002) and have been shown to regulate mGluR1/5 signaling and trafficking (Xiao et al., 2000; Fagni et al., 2002). Of particular interest, it has been proposed that CC-Homer proteins are involved in the intracellular retention of mGluR1/5 (Xiao et al., 2000; Fagni et al., 2002). We hypothesized that cocaine-induced alterations of CB1R, mGluR5, or CC-Homer levels may be at the origin of the elimination of eCB-LTD in the NAc of cocaineexposed mice. In agreement with this idea, immunoblots using a pan-Homer antibody revealed that CC-Homer levels are dramatically increased in NAc from mice that received a single injection of cocaine (Fig. 1b). The present observation that a single cocaine exposure selectively enhances CC-Homer protein levels adds to the body of evidence identifying the Homer protein family as a critical substrate of cocaine-induced neuronal alterations (Xiao et al., 2000; Fagni et al., 2002). We next tested the duration of the action of a single cocaine exposure and observed that 1 week after cocaine administration, both eCB-LTD and CC-Homer protein levels were back to normal (Fig. 1c), strongly suggesting a functional correlation between the occurrence of eCB-LTD and CCHomer expression levels.

\section{The effects of cocaine on eCB-LTD and CC-Homer levels depend on $\mathrm{D}_{1} \mathrm{R}$ and NMDAR}

Many behavioral or biochemical effects of cocaine implicate $D_{1} R$ and glutamate NMDAR (Kalivas, 1995; Hummel and Unterwald, 2002). We reasoned that $D_{1} R$ and/or NMDAR activation could be necessary to the cocaine-induced alterations of synaptic plasticity. In accord with this hypothesis, we found that the effects of cocaine were absent in $\mathrm{D}_{1} \mathrm{R}$-null mutant mice (Drago et al., 1994) (Fig. 2a) and were prevented when cocaine was coadministered with the selective $\mathrm{D}_{1} \mathrm{R}$ antagonist $\mathrm{SCH} 23390$ in wild-type mice (Fig. 2a) (Drago et al., 1994; Brady et al., 2003). Single in vivo 

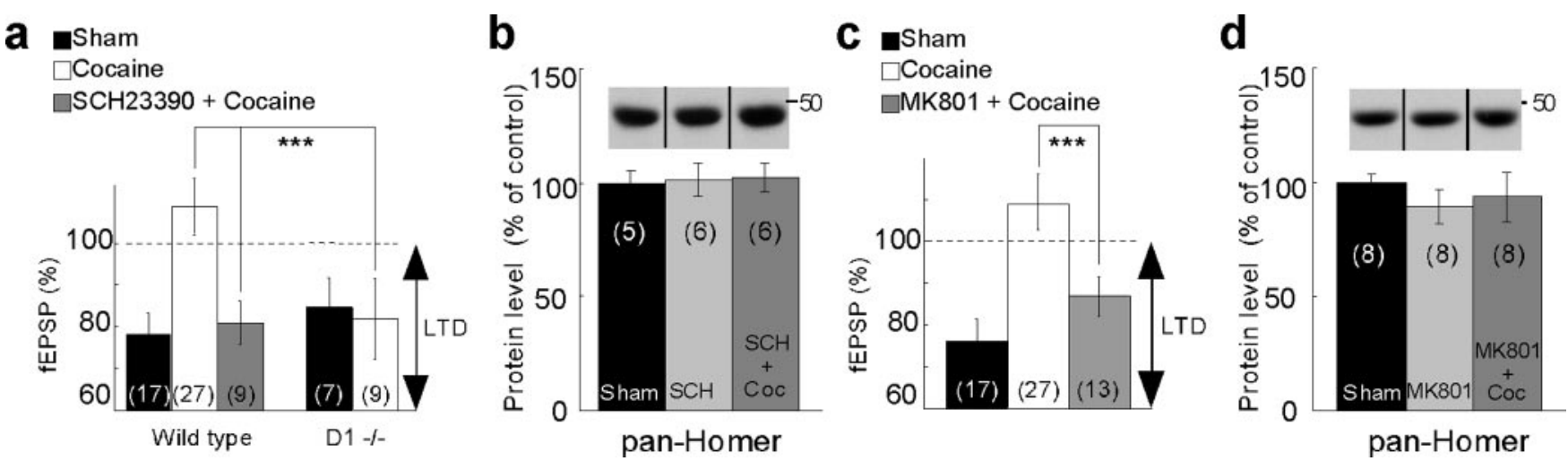

Figure 2. Role of $D_{1} R$ and NMDAR in the cocaine-induced blockade of eCB-LTD. $a$, Cocaine-induced inhibition of eCB-LTD was prevented by a $D_{1} R$ antagonist. Animals that had received $S C H 23390$ $\left(0.5 \mathrm{mg} / \mathrm{kg}\right.$ ) displayed eCB-LTD when coinjected with cocaine $\left(n=9\right.$; ${ }^{* * *} p<0.05$ compared with cocaine alone). $D_{1} R-/-$ mice display normal eCB-LTD ( $\left.n=7\right)$ but were insensitive to cocaine administration compared with wild type $\left(n=9 ;{ }^{* *} p<0.05\right)$. The dashed line represents $100 \% . b$, Representative Western blots of animals administered saline (sham), SCH23390( $\mathrm{SCH} ; 0.5 \mathrm{mg} / \mathrm{kg}$ ) alone, or SCH23390 plus cocaine (SCH + $\mathrm{Coc}$ ) in vivo. The blots show protein levels for CC-Homer using a pan-Homer antibody in the NAc $1 \mathrm{~d}$ after injection. Densitometry measurements are expressed as percentage of control \pm SEM. In SCH23390-injected animals, single cocaine exposure $(n=6)$ did not alter CC-Homer protein levels in the NAc, compared with saline $(n=5 ; p>0.05)$ and SCH23390 alone ( $n=6 ; p>0.05)$. c, Cocaine-induced inhibition of eCB-LTD is prevented by an NMDAR antagonist. Animals receiving MK801 display normal eCB-LTD when coinjected with cocaine ( $n=13 ;{ }^{* * *} p<0.05$ compared with cocaine alone). The dashed line represents $100 \%$. $d$, Representative Western blots of animals administered saline (sham), MK801 (1 mg/kg) alone, or MK801 plus cocaine (MK801 + Coc) in vivo. The blots show protein levels for CC-Homer using a pan-Homer antibody in the NAc $1 \mathrm{~d}$ after injection. Densitometry measurements are expressed as percentage of control \pm SEM. In MK801-injected animals, single cocaine exposure $(n=8)$ did not alter CC-Homer protein levels in the NAc, compared with saline $(n=8 ; p>0.05)$ and MK801 alone $(n=8 ; p>0.05)$.

injection with the specific $\mathrm{D}_{1} \mathrm{R}$ agonist SKF38393 (10 mg/kg) also completely blocked eCB-LTD, suggesting that $\mathrm{D}_{1} \mathrm{R}$ activation is both necessary and sufficient to the cocaine-induced alterations of synaptic plasticity in the NAc (fEPSP was $102.2 \pm 4.5 \%$ of baseline; $n=14 ; 50$ min after tetanus; $p>0.05$ compared with sham). Moreover, when cocaine was coadministered with the selective noncompetitive NMDAR antagonist MK801 in wildtype mice (Valjent et al., 2001), eCB-LTD was not blocked (Fig. $2 c$ ). These data show that blockade of $\mathrm{D}_{1} \mathrm{R}$ - and/or NMDARmediated functions prevents the processes initiated by cocaine and the following obliteration of eCB-LTD.

We next tested whether $\mathrm{D}_{1} \mathrm{R}$ and NMDAR inhibitors also significantly interfere with the cocaine-induced enhancement of CC-Homer expression levels. As shown in Figure 2, preventing the cocaine blockade of eCB-LTD with either the $\mathrm{D}_{1} \mathrm{R}$ (Fig. 2b) or the NMDAR (Fig. 2d) antagonist also prevented the cocaineinduced enhancement of CC-Homer expression levels. These experiments reinforced the idea of a functional correlation between CC-Homer levels and the ability to induce eCB-LTD.

\section{A single in vivo cocaine exposure does not alter $\mathrm{CB} 1 \mathrm{R}$ function, CB1R protein expression level, or the endogenous cannabinoid tone}

Cocaine exposure could cause functional tolerance of CB1R and thereby lead to an apparent abolition of eCB-mediated LTD. This possibility was excluded on the basis of the following observations: first, we verified that bath application of the selective CB1R agonist (-)-cis-3-[2-hydroxy-4-(1,1-dimethylheptyl)phenyl]trans-4-(3-hydroxypropyl)cyclohexanol (CP55,940) (10 $\mu \mathrm{M})$ caused a similar fEPSP depression in NAc slices prepared from cocaine- and sham-treated mice (Fig. $3 a$ ). Second, it was found that the total protein levels of CB1R remained unaffected by cocaine treatment (Fig. 3b), arguing against the idea that cocaine reduced CB1R expression levels. Recent evidence suggests that in the limbic forebrain, dopamine receptor activity can alter the eCB tone (Patel et al., 2003); in particular, both cocaine and the $\mathrm{D}_{1} \mathrm{R}$ antagonist SCH23390 altered eCB content. Because the mice were treated with both cocaine and $\mathrm{SCH} 23390$, the possibility
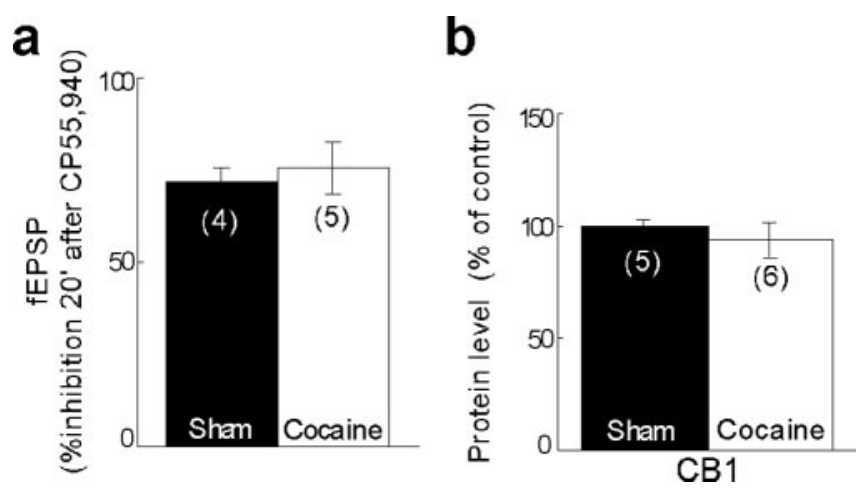

Figure 3. $\quad(B 1 R$ presynaptic functions and protein levels are not altered by single in vivo cocaine exposure. $a$, CB1R-mediated fEPSP inhibition. Single cocaine injection $(n=5)$ did not alter the CB1R-mediated fEPSP inhibition [compared with sham; $n=4 ; 20$ min after application of the CB1R agonist (P55,940 $(10 \mu \mathrm{M}) ; p>0.05]$. $b$, Densitometry measurements expressed as percentage of control \pm SEM. Single cocaine exposure $(n=6)$ did not alter CB1R protein levels in the NAc, compared with saline $(n=5 ; p>0.05)$.

existed that the modulations of synaptic plasticity were caused by changes in the eCB tone. Thus, we measured the effects of the specific CB1R antagonist $N$-piperidino-5-(4-chlorophenyl)-1-(2,4-dichlorophenyl)-4-methylpyrazole-3-carboxamide (SR141716A) on baseline synaptic transmission after in vivo exposure to cocaine or SCH23390. Bath application of SR141716A (30 min; $5 \mu \mathrm{M}$ ) had no effect on synaptic responses in NAc slices from cocaine- or SCH23390-treated mice [fEPSP was $99 \pm 4 \%(n=6)$ and $99 \pm 5 \%$ $(n=4)$ of baseline in NAc slices prepared from cocaine- and SCH23390-treated animals, respectively]. Thus, durable alterations of eCB content after in vivo exposure to cocaine or the $\mathrm{D}_{1} \mathrm{R}$ antagonist are unlikely to account for the changes in synaptic plasticity observed in the NAc of cocaine-treated mice.

The effects of single cocaine exposure on NAc LTD are restricted to eCB-mediated plasticity

Another possibility was that cocaine caused a nonselective blockade of LTD at prelimbic cortex-NAc synapses. At these synapses, 

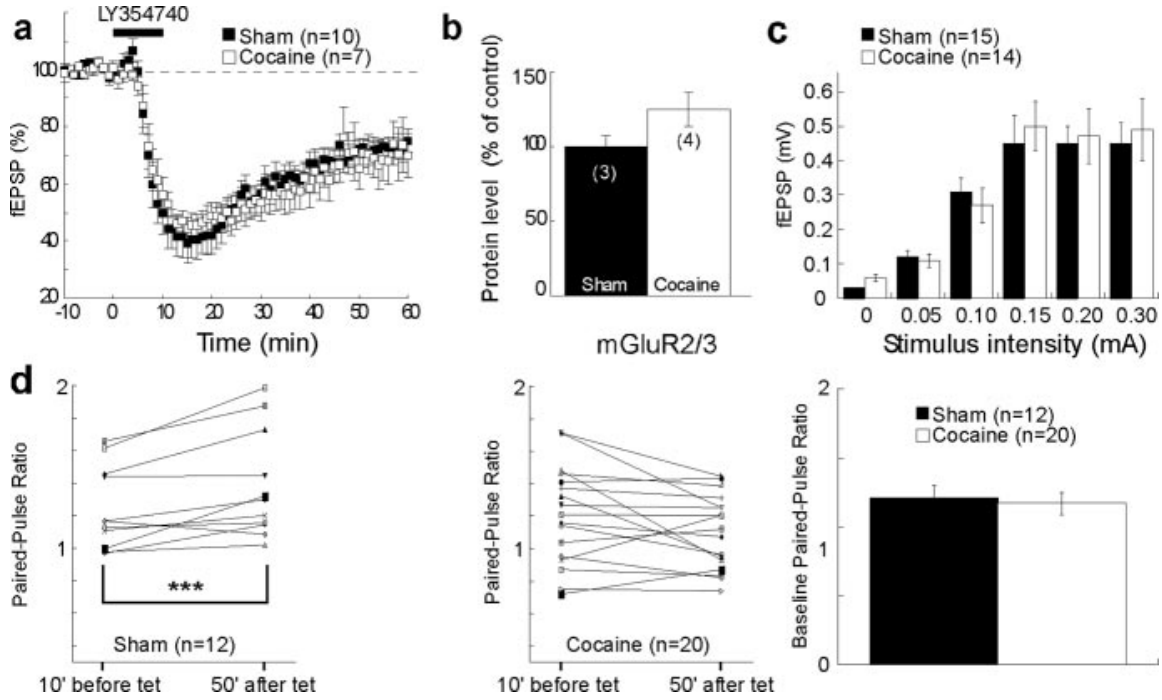

Figure 4. A single in vivo cocaine exposure does not induce a generalized alteration of prefrontal cortex-NAc synapses. $a$, Single cocaine injection $(n=7)$ did not alter mGluR2/3-LTD [compared with sham; $n=10 ; 60$ min after application of the selective mGluR2/3 agonist LY354740 (200 nm) for $10 \mathrm{~min} ; p>0.05$ ]. The dashed line represents 100\%. $b$, Single cocaine exposure did not change NAc protein levels of mGluR2/3. Densitometry measurements are expressed as percentage of control \pm SEM. Single cocaine exposure $(n=4)$ did not alter mGluR2/3 protein levels in the NAc, compared with saline $(n=3 ; p>0.05)$. $c$, Input- output curves for sham-treated mice and mice treated with a single injection of cocaine were similar. $d$, Left, Pairedpulse ratios were augmented after eCB-LTD induction in sham animals $(1.21 \pm 0.0910$ min before tetanus compared with $1.36 \pm$ 0.0950 min after tetanus; $n=12 ;{ }^{* * *} p<0.05$ but not in cocaine-treated animals ( $1.17 \pm 0.0810$ min before tetanus compared with $1.12 \pm 0.0950$ min after tetanus; $n=20 ; p>0.05$ ). Right, Baseline paired-pulse ratios were identical in vehicle- and cocaine-treated animals [1.21 $\pm 0.09(n=12)$ in sham animals compared with $1.17 \pm 0.08(n=20)$ in cocaine-treated animals; $p>0.05]$, suggesting that basal probability of transmitter release was unchanged after cocaine injection. tet, Tetanus.
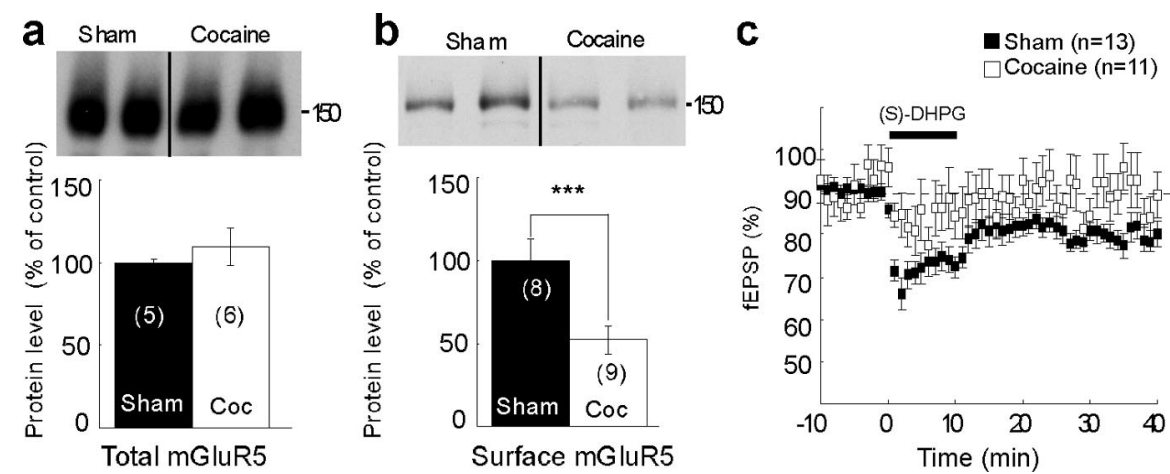

Figure 5. Cocaine administration causes a loss of surface mGluR5. $a$, Single cocaine exposure did not change total NAc protein levels of mGluR5. Representative Western blots of animals administered saline (sham) or cocaine in vivo are shown. The blots demonstrate protein levels for mGluR5 using an mGluR5 antibody in the NAc $1 \mathrm{~d}$ after injection. Densitometry measurements are expressed as percentage of control \pm SEM. Single cocaine exposure $(n=6)$ did not alter total mGluR5 protein levels in the NAc, compared with saline $(n=5 ; p>0.05) . b$, Representative Western blots of animals administered in vivo with saline (sham) or cocaine showing biotinylated mGluR5 in the NAc $1 \mathrm{~d}$ after injection. Densitometry measurements are expressed as percentage of control \pm SEM. Single cocaine exposure $(n=9)$ decreased biotinylated mGluR5 protein levels in the NAc, compared with saline $\left(n=8 ;{ }^{* * *} p<0.05\right)$. c, Average time courses of mGluR5-mediated LTD. Single cocaine injection $(n=11)$ abolished mGluR5-LTD [compared with sham; $n=13 ; 40$ min after application of the selective mGluR5 agonist (S)-DHPG (100 $\mu \mathrm{m})$ for $10 \mathrm{~min} ; p<0.05$ ]. Coc, Cocaine.

we have reported previously that synaptic and pharmacological activation of presynaptic mGluR2/3 induces LTD (Robbe et al., 2002a). As shown in Figure $4 a$, LTD induced by the selective mGluR2/3 agonist LY354740 (200 nM for $10 \mathrm{~min}$ ) (Robbe et al., $2002 a$ ) is normal after a single in vivo exposure to cocaine. Accordingly, the total protein levels of $\mathrm{mGluR} 2 / 3$ remained unaffected by cocaine treatment (Fig. 4b). Thomas et al. (2001) have reported that single cocaine exposure does not affect postsynaptic NMDAR-dependent LTD. Together, these data indicate that cocaine specifically abolishes eCB-mediated plasticity, whereas neither presynaptic mGluR2/3-dependent LTD nor postsynaptic NMDA-dependent LTD (Thomas et al., 2001) were modified. Moreover, input-output curves obtained in measuring fEPSP amplitudes evoked by an increasing range of stimulation intensities were similar in the two groups of mice, suggesting that in the NAc, the efficacy of synaptic transmission is unchanged in slices from cocaine-treated mice (Fig. 4c). Finally, it was verified that the pairedpulse ratio, a form of short-term plasticity sensitive to eCB-mediated LTD (Fig. $4 d$, left), was unaffected in cocaine-treated animals (Fig. $4 d$, right), suggesting that eCB-LTD is not already induced in cocaine-injected mice. Collectively, this indicates that single cocaine exposure does not induce a generalized alteration in the ability of the prefrontal cortexNAc synapses to express synaptic plasticity.

Single cocaine administration strongly reduces mGluR5 surface expression and mGluR5 synaptic actions

Finally, we searched for a mechanism that could link elevated levels of CCHomer and the cocaine-induced block of retrograde signaling. Postsynaptic mGluR5 activation is necessary and sufficient to produce eCB-LTD (Robbe et al., 2002b), and converging reports indicate that CC-Homer proteins control the surface expression of mGluR5 (Xiao et al., 2000). To test the hypothesis that elevation of CC-Homer levels can induce the intracellular retention of mGluR5 (Xiao et al., 2000; Fagni et al., 2002) and a corresponding reduction in the ability of mGluR5 to translate anterograde glutamate signaling into retrograde eCB signaling, a surface biotinylation assay of mGluR5 was performed. It was first observed that total mGluR5 levels remained unaffected after exposure to cocaine (Fig. $5 a$ ). In contrast, a single in vivo exposure to cocaine is indeed associated with a large decrease in the surface expression of mGluR5 (Fig. 5b), supporting the notion that cocaine-induced loss of eCB retrograde signaling is attributable to reduced functions of postsynaptic mGluR5. We have described previously that postsynaptic mGluR5s are crucially involved in mediating the eCBdependent LTD and that tetanus-induced eCB-LTD can be mimicked by direct pharmacological stimulation of mGluR5 with the selective group I mGluR agonist (S)-3,5-dihydroxyphenylglycine [(S)-DHPG] (Robbe et al., 2002b). Thus, if mGluR5s are removed from the surface in response to cocaine exposure, one expectation is that mGluR5 agonist-induced 

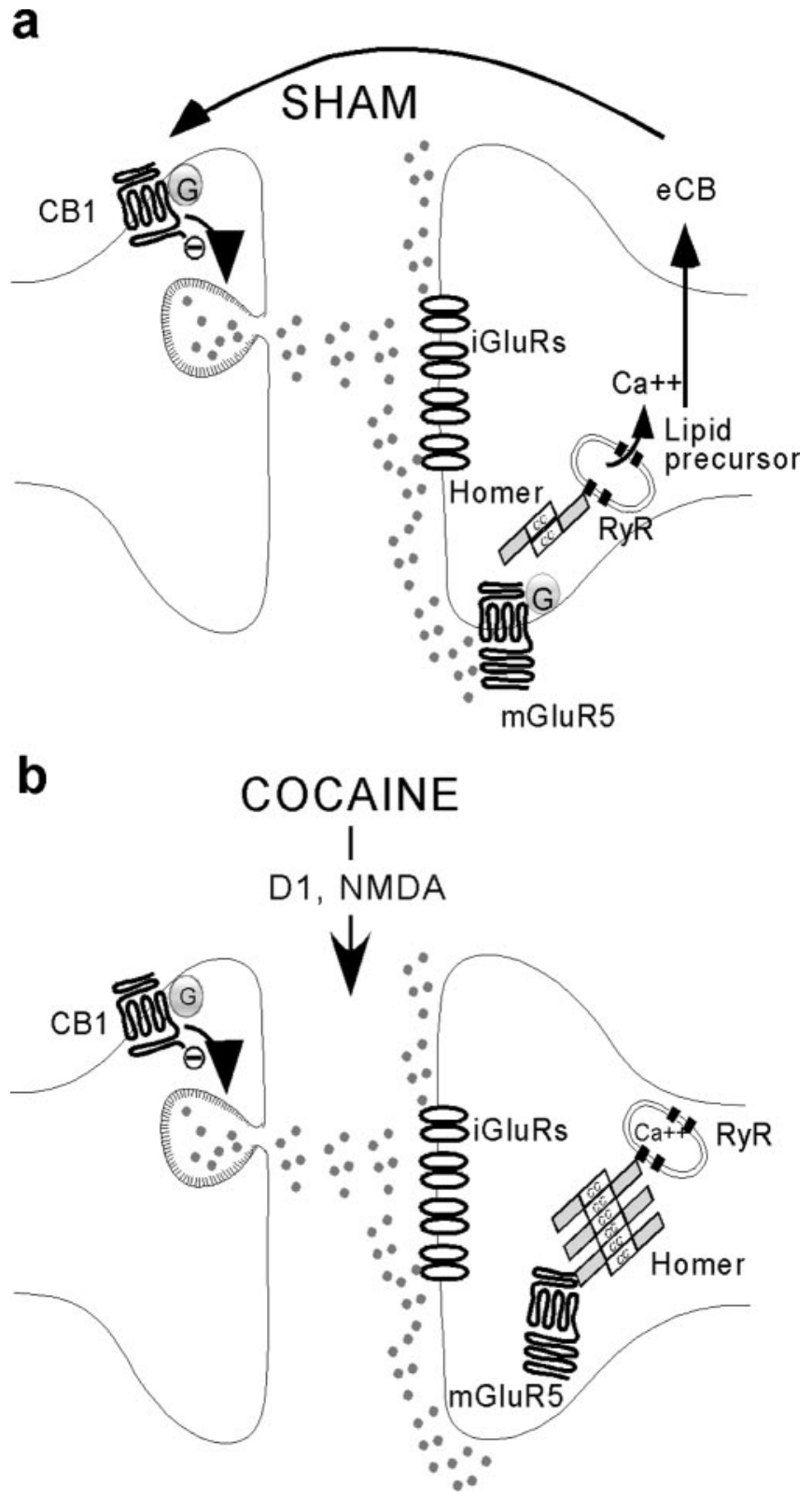

Figure 6. Schematic illustrating the interactions between the eCB-mediated retrograde signaling and the CC-Homer family of scaffolding proteins at excitatory NAc synapses. $a$, In naive or sham animals, retrograde eCB-LTD is normally induced after activation of postsynaptic mGluR5 and production of eCB. $b$, One day after cocaine exposure, heightened protein levels of CCHomer caused the intracellular retention of postsynaptic mGluR5. The associated loss of postsynaptic mGluR5 surface expression prevents the induction of eCB-dependent retrograde signaling. The effects of cocaine on eCB-dependent $L T D$ require $D_{1} R$ and NMDAR. RyR, Ryanodine receptor; G, G-protein; iGluRs, ionotropic GluRs.

LTD is absent in cocaine-treated animals. Indeed, in NAc slices prepared from cocaine-exposed mice, both mGluR5mediated acute inhibition of excitatory transmission and LTD were markedly reduced (Fig. $5 c$ ).

\section{Discussion}

Here we identify a new mechanism by which cocaine alters synaptic plasticity in the endogenous brain reward system: retrograde LTD mediated by eCBs is eliminated in response to a single in vivo exposure to cocaine. The data show that single in vivo exposure to cocaine (in a $\mathrm{D}_{1} \mathrm{R}$ - and NMDAR-dependent manner) increases the expression of CC-Homer. We propose that the ensuing substantial reduction in mGluR5 surface expression causes a marked reduction in the ability of mGluR5 to translate anterograde glutamate signaling into retrograde eCB signaling (Fig. 6).

Our data link changes in the surface expression of metabotropic glutamate receptors and addictive-drug-induced alteration of synaptic plasticity. Trafficking of ionotropic glutamate receptors is a well recognized mechanism underlying synaptic plasticity associated with elementary forms of memory (e.g., long-term potentiation and LTD) (Contractor and Heinemann, 2002), and the present data show that trafficking of metabotropic glutamate receptors also plays a fundamental role in the synaptic plasticity underlying adaptations to addictive drugs.

This study also adds to several converging reports showing the central role of the Homer protein family as a critical substrate of cocaine-induced neuronal adaptations (Xiao et al., 2000; Fagni et al., 2002). The first identified member of the Homer family was Homerla, a short Homer lacking the CC domain which thus competes with CC-Homer and disassembles the signaling complexes formed between CC-Homer and its partners (i.e., mGluR1/5, Shank, intracellular calcium store, etc.) (Xiao et al., 2000). Interestingly, Homer la protein is an immediate early gene product that is rapidly and transiently induced by intense neuronal activity and during the first hours after acute cocaine administration (Brakeman et al., 1997). We propose that the elevation of CC-Homer observed $1 \mathrm{~d}$ after in vivo cocaine exposure is an early counter-adaptation to the Homerla-induced reduction of CC-Homer functions. Moreover, CC-Homer proteins also play a role in the adaptations to prolonged cocaine administration: 3 weeks after discontinuing 1 week of daily cocaine, there is a significant reduction in CC-Homer levels in the NAc (Swanson et al., 2001) that participates in the expression of behavioral sensitization (Ghasemzadeh et al., 2003). Thus, a possible interpretation of these data is that a single cocaine administration results in the elevation of CC-Homer expression, whereas repeated cocaine exposure triggers a compensatory mechanism, ultimately decreasing CC-Homer protein levels.

Our results reinforce the idea that the eCB system is involved in the behavioral actions of cocaine and in particular, the observation that $\mathrm{CB} 1 \mathrm{R}$ antagonists can induce cocaine relapse (De Vries et al., 2001). It is noteworthy that eCB-LTD in the NAc is reduced by chronic exposure to $\Delta$-9-tetrahydrocannabinol (Hoffman et al., 2003) and that CB1R-null mutant mice are less sensitive to the rewarding properties of opiates and nicotine (Ledent et al., 1999; Castane et al., 2002). Thus the emerging picture is that the eCB system is a prominent player in the actions of addictive drugs.

At prefrontal cortex-NAc synapses, eCB-LTD might participate in a negative feedback loop reducing the strength of excitatory synapses during sustained cortical activity. Behavioral sensitization to cocaine is accompanied by a decrease in excitatory drive to the NAc (Thomas et al., 2001) and a reduction in NAc basal extracellular glutamate (Pierce et al., 1996). Thus the abolition of eCB-LTD in the NAc of cocaine-exposed animals might serve as a compensatory mechanism to counterbalance the general decrease in glutamatergic activity measured in response to cocaine. In support of this idea, a recent microdialysis study in models of behavioral sensitization and drug-seeking has demonstrated an enhanced release of glutamate after a cocaine-priming injection at prefrontal cortex-NAc synapses (McFarland et al., 2003). 


\section{References}

Beurrier C, Malenka RC (2002) Enhanced inhibition of synaptic transmission by dopamine in the nucleus accumbens during behavioral sensitization to cocaine. J Neurosci 22:5817-5822.

Brady AM, Glick SD, O’Donnell P (2003) Changes in electrophysiological properties of nucleus accumbens neurons depend on the extent of behavioral sensitization to chronic methamphetamine. Ann NY Acad Sci 1003:358-363.

Brakeman PR, Lanahan AA, O’Brien R, Roche K, Barnes CA, Huganir RL, Worley PF (1997) Homer: a protein that selectively binds metabotropic glutamate receptors. Nature 386:284-288.

Castane A, Valjent E, Ledent C, Parmentier M, Maldonado R, Valverde O (2002) Lack of CB1 cannabinoid receptors modifies nicotine behavioural responses, but not nicotine abstinence. Neuropharmacology 43:857-867.

Chiamulera C, Epping-Jordan MP, Zocchi A, Marcon C, Cottiny C, Tacconi S, Corsi M, Orzi F, Conquet F (2001) Reinforcing and locomotor stimulant effects of cocaine are absent in mGluR5 null mutant mice. Nat Neurosci 4:873-874.

Contractor A, Heinemann SF (2002) Glutamate receptor trafficking in synaptic plasticity. Sci STKE 2002:RE14.

De Vries TJ, Shaham Y, Homberg JR, Crombag H, Schuurman K, Dieben J, Vanderschuren LJ, Schoffelmeer AN (2001) A cannabinoid mechanism in relapse to cocaine seeking. Nat Med 7:1151-1154.

Drago J, Gerfen CR, Lachowicz JE, Steiner H, Hollon TR, Love PE, Ooi GT, Grinberg A, Lee EJ, Huang SP, Jose PA, Sibley DR, Westphal H (1994) Altered striatal function in a mutant mouse lacking $\mathrm{D}_{1 \mathrm{~A}}$ dopamine receptors. Proc Natl Acad Sci USA 91:12564-12568.

Fagni L, Worley PF, Ango F (2002) Homer as both a scaffold and transduction molecule. Sci STKE 2002:RE8.

Ghasemzadeh MB, Permenter LK, Lake R, Worley PF, Kalivas PW (2003) Homerl proteins and AMPA receptors modulate cocaine-induced behavioural plasticity. Eur J Neurosci 18:1645-1651.

Goto Y, O'Donnell P (2001) Network synchrony in the nucleus accumbens in vivo. J Neurosci 21:4498-4504.

Harrison JM, Allen RG, Pellegrino MJ, Williams JT, Manzoni OJ (2002) Chronic morphine treatment alters endogenous opioid control of hippocampal mossy fiber synaptic transmission. J Neurophysiol 87:2464-2470.

Hoffman AF, Oz M, Caulder T, Lupica CR (2003) Functional tolerance and blockade of long-term depression at synapses in the nucleus accumbens after chronic cannabinoid exposure. J Neurosci 23:4815-4820.

Hummel M, Unterwald EM (2002) D1 dopamine receptor: a putative neurochemical and behavioral link to cocaine action. J Cell Physiol 191:17-27.

Hyman SE, Malenka RC (2001) Addiction and the brain: the neurobiology of compulsion and its persistence. Nat Rev Neurosci 2:695-703.

Ingram SL, Vaughan CW, Bagley EE, Connor M, Christie MJ (1998) Enhanced opioid efficacy in opioid dependence is caused by an altered signal transduction pathway. J Neurosci 18:10269-10276.

Jackson HC, Nutt DJ (1993) A single preexposure produces sensitization to the locomotor effects of cocaine in mice. Pharmacol Biochem Behav 45:733-735.

Kalivas PW (1995) Interactions between dopamine and excitatory amino acids in behavioral sensitization to psychostimulants. Drug Alcohol Depend 37:95-100.
Ledent C, Valverde O, Cossu G, Petitet F, Aubert JF, Beslot F, Bohme GA, Imperato A, Pedrazzini T, Roques BP, Vassart G, Fratta W, Parmentier M (1999) Unresponsiveness to cannabinoids and reduced addictive effects of opiates in CB1 receptor knockout mice. Science 283:401-404.

Martin G, Ahmed SH, Blank T, Spiess J, Koob GF, Siggins GR (1999) Chronic morphine treatment alters NMDA receptor-mediated synaptic transmission in the nucleus accumbens. J Neurosci 19:9081-9089.

McFarland K, Lapish CC, Kalivas PW (2003) Prefrontal glutamate release into the core of the nucleus accumbens mediates cocaine-induced reinstatement of drug-seeking behavior. J Neurosci 23:3531-3537.

Melis M, Camarini R, Ungless MA, Bonci A (2002) Long-lasting potentiation of GABAergic synapses in dopamine neurons after a single in vivo ethanol exposure. J Neurosci 22:2074-2082.

Nestler EJ (2001a) Molecular basis of long-term plasticity underlying addiction. Nat Rev Neurosci 2:119-128.

Nestler EJ (2001b) Molecular neurobiology of addiction. Am J Addict 10:201-217.

Patel S, Rademacher DJ, Hillard CJ (2003) Differential regulation of the endocannabinoids anandamide and 2-arachidonylglycerol within the limbic forebrain by dopamine receptor activity. J Pharmacol Exp Ther 306:880-888.

Pierce RC, Bell K, Duffy P, Kalivas PW (1996) Repeated cocaine augments excitatory amino acid transmission in the nucleus accumbens only in rats having developed behavioral sensitization. J Neurosci 16:1550-1560.

Robbe D, Alonso G, Chaumont S, Bockaert J, Manzoni OJ (2002a) Role of $\mathrm{P} / \mathrm{Q}-\mathrm{Ca}^{2+}$ channels in metabotropic glutamate receptor 2/3-dependent presynaptic long-term depression at nucleus accumbens synapses. J Neurosci 22:4346-4356.

Robbe D, Kopf M, Remaury A, Bockaert J, Manzoni OJ (2002b) Endogenous cannabinoids mediate long-term synaptic depression in the nucleus accumbens. Proc Natl Acad Sci USA 99:8384-8388.

Robbe D, Bockaert J, Manzoni OJ (2002c) Metabotropic glutamate receptor 2/3-dependent long-term depression in the nucleus accumbens is blocked in morphine withdrawn mice. Eur J Neurosci 16:2231-2235.

Saal D, Dong Y, Bonci A, Malenka RC (2003) Drugs of abuse and stress trigger a common synaptic adaptation in dopamine neurons. Neuron 37:577-582.

Swanson CJ, Baker DA, Carson D, Worley PF, Kalivas PW (2001) Repeated cocaine administration attenuates group I metabotropic glutamate receptor-mediated glutamate release and behavioral activation: a potential role for Homer. J Neurosci 21:9043-9052.

Thomas MJ, Beurrier C, Bonci A, Malenka RC (2001) Long-term depression in the nucleus accumbens: a neural correlate of behavioral sensitization to cocaine. Nat Neurosci 4:1217-1223.

Ungless MA, Whistler JL, Malenka RC, Bonci A (2001) Single cocaine exposure in vivo induces long-term potentiation in dopamine neurons. Nature 411:583-587.

Valjent E, Pages C, Rogard M, Besson MJ, Maldonado R, Caboche J (2001) Delta 9-tetrahydrocannabinol-induced MAPK/ERK and Elk-1 activation in vivo depends on dopaminergic transmission. Eur J Neurosci 14:342-352.

Williams JT, Christie MJ, Manzoni O (2001) Cellular and synaptic adaptations mediating opioid dependence. Physiol Rev 81:299-343.

Xiao B, Tu JC, Worley PF (2000) Homer: a link between neural activity and glutamate receptor function. Curr Opin Neurobiol 10:370-374. 